\title{
Proposal for standard methods and procedure for guinea pig carcass evaluation, jointing and tissue separation
}

\author{
Davinia Sánchez-Macías $^{\mathrm{a} *}$ (D), Noemí Castro ${ }^{\mathrm{b}}$, Miguel A. Rivero ${ }^{\mathrm{c}}$, Anastasio Argüello ${ }^{\mathrm{b}}$ and Antonio Morales-delaNuez ${ }^{\mathrm{d}}$ \\ ${ }^{a}$ Department of Agroindustrial Engineering. Universidad Nacional de Chimborazo, Riobamba, Ecuador; ${ }^{b}$ Animal Science \\ Department, Universidad de las Palmas de Gran Canaria, Arucas, Spain; ' Department of Veterinary Histology and Pathology, \\ Institute for Animal Health (IUSA), Universidad de las Palmas de Gran Canaria, Arucas, Spain; ${ }^{d}$ Facultad de Ciencia Pecuarias, \\ Escuela Superior Politécnica de Chimborazo, Riobamba, Ecuador
}

(Received 29 December 2014; accepted 7 January 2015)

\begin{abstract}
The South American guinea pig rodent has become a livestock animal acceptable for human consumption in different parts of the world. Its white meat has a great potential as a new protein source, and its social and economic importance for different human populations is considered key for development. Scarce data are found in the literature when the statistical livestock information is checked, and few researches have been done about morphological characteristics of guinea pigs carcasses. These works do not follow the same procedures, using different criteria, overall the jointing, making it difficult to compare different studies. The aim of the present study is to suggest a practical and normalized method to analyse the guinea pig carcass characteristics allowing their evaluation. It describes the main traits to be considered from the birth of the animal to the carcass analysis. This work concerns: (1) growth, feeding, pre-slaughter and slaughter processing, (2) method for the definition, hanging and presentation of the carcass, (3) carcass morphological characteristics, (4) jointing procedure based on four anatomically defined regions, (5) methods for evaluating meat $\mathrm{pH}$ and colour and (6) method for tissue separation. This proposal could be useful to compare data of these animals under different conditions.
\end{abstract}

Keywords: guinea pig; carcass; jointing; tissue distribution

\section{Introduction}

Guinea pig (Cavia porcellus), a South American rodent, is not only an animal for scientific research. This species has different breeds that have become livestock animals acceptable for consumption by the people. Its meat, similar in appearance to rabbit or chicken meat, has been consumed for centuries in Andean region, where originally domesticated by indigenous people. Now, we attend an exponential grown around the world, mainly in some Asian and African developing countries, where their potential as a new protein source is great (Lammers et al. 2009), and its social and economic importance in different human populations is considered key for development (Matthiesen et al. 2011). The information about the global guinea pig meat production is not well known, and scarce data are found in the literature when the statistical livestock information of the different countries is checked. High prolificacy and diet flexibility, as well as a great adaptability to wide range of housing and management approaches, are critical traits of guinea pig raised for meat production in both, home consumption and marketing in the context or rural smallholders (Lammers et al. 2009).

The biological, ecological and economic advantages of guinea pigs deserve further attention by those working to alleviate global poverty and food insecurity. These strains, with a weight range $1.5-2.5 \mathrm{~kg}$, offer a reasonable economic prospect for agricultural and diversification under suitable conditions (Lammers et al. 2009).

Despite the importance of guinea pig meat production, the knowledge about the carcass morphological characteristics, like the quality or the tissue separation, is very limited. A technical regulation exists in some Andean countries (Indecopi 2006) about the definition, classification and criteria of carcass and meat of guinea pigs. However, this technical regulation is focused in the carcass processing with commercial objectives, and it lacks of information about the meat quality based on anatomical studies. It proposes a jointing method dividing each half carcass into two quarters: forequarters and hindquarters, following the typical cuts that are available for consumption in other livestock animals.

Differences in jointing or cutting systems exist for different species, leading to difficulties in comparing results from different regions in the world. For this reason, there are in the literature standard methods and procedures which describe how to analyse the carcass quality, for example, for rabbit (Blasco \& Ouhayoun

*Corresponding author. Email: dsanchez@unach.edu.ec 
1993), pig (Walstra \& Merkus 1995), goat or sheep (Colomer-Rocher et al. 1987, 1988).

The aim of the present study is to suggest practical and normalized method to analyse the guinea pig carcass morphological characteristics allowing their evaluation based on anatomical guidelines. This proposal of standard method, modified from the standard method proposed for goats by Colomer-Rocher et al. (1987), could be used for researchers and technicians to compare data of these animals under different conditions.

\section{Breeding conditions and sample definition}

Although the proposal concerns carcass traits, some recommendations for growth, consumption and breeding measurements or definition are given according to Blasco and Ouhayoun (1993).

\subsection{Breed}

It is necessary and important to specify the breed of C. porcellus since different breeds exist for this species.

\subsection{Age and growing period}

It is recommended to specify the weaning age and growing period if it is fixed time. If weaning is made in a fixed weight, the weight should be provided.

\subsection{Feeding management}

It is important to know the composition, nutritional values and amount of feed, overall in experiments based on different diets or nutritional managements.

\subsection{Fasting}

It can be from solids, liquids or both. It must be specified the type of fasting and its duration. For guinea pigs, it is generally recommended at 12-14 hours before slaughtering (according to Kouakou et al. 2013).

\subsection{Slaughter shock method}

It is necessary to describe the type of shock: electrical (voltage and duration), neck hit or others. Mota-Rojas et al. (2012) reported the effects of electrical stunning method on metabolism changes, gas exchange and acid base imbalance in blood, as well as its impact on guinea pig meat quality.

\subsection{Others considerations}

It is required to determine the genetic origin of the animals, sex and physiological stage (lactation, pregnancy, young animals, adults, etc.), among other factors (special diets, production systems, hormonal treatments, castration, etc.).

\section{Carcass preparation and presentation}

In order to standardize carcass appearance and the measurements required for carcass evaluation, it is necessary to define, hand and present it uniformly, according to Colomer-Rocher et al. (1987).

\subsection{Definition of guinea pig carcass}

The proposed definition for carcass is:

The carcass of the animal after slaughtered, bloodless and scalded $\left(60-70^{\circ} \mathrm{C}\right.$ during $45-60$ seconds), comprises the body after removal the hair, the head (between the occipital bone and first cervical vertebra), the hand and the feet at carpo-metacarpal and tarso-metatarsal joints, respectively, and the viscera. The carcass retains the skin, lateral portions of the diaphragm and the perirenal and pelvic fat deposits. Any alteration of this definition of the carcass should be mentioned.

\subsection{Slaughter data recording}

- Farm live weight (FLW). Weight of the animal at farm before transport and fasting. If the period ends at fix day, the weight interval must be provided.

- Live weight at slaughter (LWS). Weight of the animal after transport and fasting.

- Empty body weight (EBW). It is the difference between live weight at slaughter and gastrointestinal and urinary contents.

- Full gastrointestinal tract weight (FGTW). The full tract weight includes the stomach, caecum and rest of the intestinal contents.

- Empty gastrointestinal tract weight (EGTW). Weight of the empty, clean and dripped gastrointestinal tract.

- Hot carcass weight (HCW). Carcass weight at $15-$ 20 min after slaughter.

- Chilled or cold carcass weight (CCW). Carcass weight after chilling at least for 15 hours (after rigour mortis is resolved; Núñez-Valle et al. 2014), hanged in a ventilated cold room $\left(0-4^{\circ} \mathrm{C}\right)$.

- Drip loss percentage (DLP). Difference calculated between hot carcass weight and chilled carcass weight divided by hot carcass weight $(\times 100)$.

- Dressing out carcass yield percentage (DCY). Weight of carcass after chilling divided by live weight at slaughter $(\times 100)$.

- Net carcass yield percentage (NCY). Carcass weight after chilling divided by empty body weight $(\times 100)$. 
If extra slaughtering data are recorded or calculated, it is recommended to describe it clearly.

\subsection{Definition of the viscera}

During the slaughter, and for specific studies, the offal must be weighed and recorded.

- Lost blood during the exsanguination (LBW). It is calculated as the difference between live weight at slaughter and weight after bled.

- Feet $(\mathrm{FeW})$. Feet cut at the carpo-metacarpal and tarso-metatarsal joints.

- Head (HeW). Weight of the hairless head, including ears.

- Lungs and trachea (LtW). Weight of these organs.

- Heart (HeW). Weight of this organ.

- Liver (LvW). Weight of the liver, excluding gall bladder.

- Gall bladder (GbW). Weight of the bladder.

- Spleen $(\mathrm{SpW})$. Weight of this organ.

- Kidney (KiW). Weight of both kidneys without perirenal fat.

- Full urogenital tract (FUgW). The urinary bladder has to be full; the weight includes the accessory genital glands (male) and the skin of the perineum with the external parts of the genital organs and anus.

- Empty Urogenital tract $(\mathrm{EUgW})$. The urinary bladder has to be empty; the weight includes the accessory genital glands (male) and the skin of the perineum with the external parts of the genital organs and anus.

- Urinary content. Difference calculated between FUgW and EUgW.

\subsection{Carcass presentation}

A standard presentation and hanging method of the carcass is necessary, overall when measurements are required. After evisceration, carcasses should be hung by a gambrel; the distance between heels must be $5 \mathrm{~cm}$. However, some morphological changes could be produced in small carcasses. In these cases, it is possible to reduce the heels distance trying to get a normal position of the gambrel.

If traditionally a different presentation of the carcass is imposed, specify under what conditions the measures are recorded and the characters are evaluated.

\section{Reference carcass characteristics}

On chilled carcass, the following linear measurements should be taken. They are limited to a minimum number considered as enough to characterize the carcass.

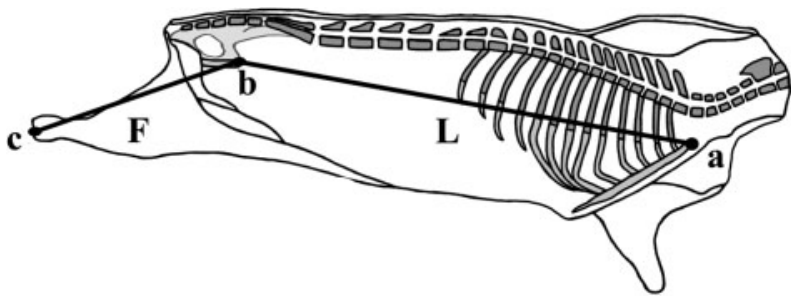

Figure 1. Guinea pig carcass measurements, schematic midsagittal view: carcass length (L), a-b distance; hid limb length (F), b-c distance.

\subsection{Linear carcass conformation measurements}

Carcass conformation measurements should be collected on carcass suspended in a gamble of constant width between lengths, described as follows (Figures 1,2 and 3).

- Carcass length (L): This distance is measured in a straight line from the cranial edge of the manubrium of the sternum to the cranial edge of the

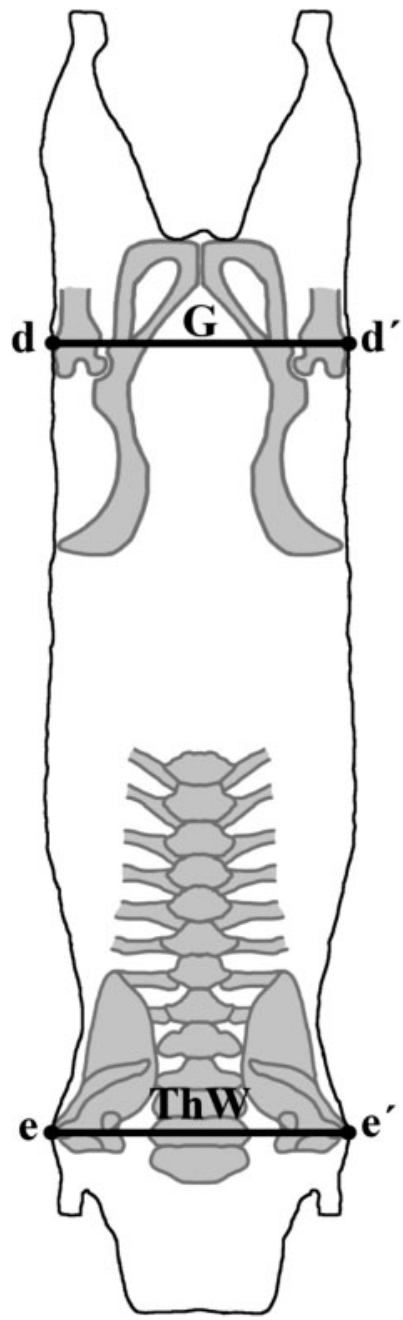

Figure 2. Guinea pig carcass measurements, schematic dorsal view: width of the buttocks $(\mathrm{G}), \mathrm{d}-\mathrm{d}^{\prime}$ distance; width of the thorax (ThW), e-e' distance. 


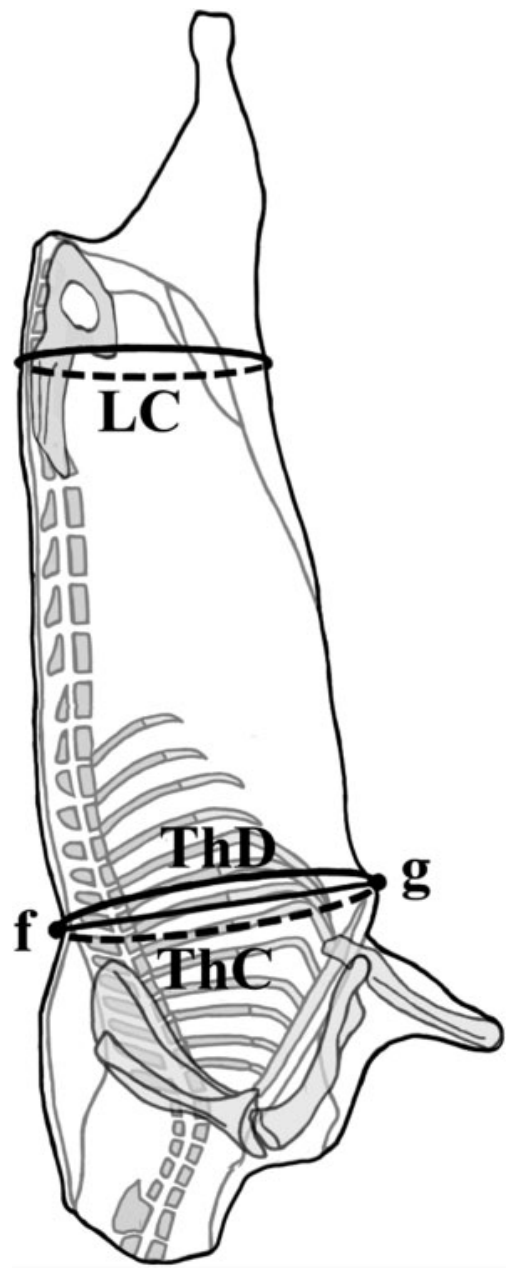

Figure 3. Guinea pig carcass measurements, schematic lateral view: lumbar circumference (LC); thorax circumference (ThC); width of the thorax $(\mathrm{ThW}), \mathrm{f}-\mathrm{g}$ distance.

pubic bone (Figure 1: $a \rightarrow b$ ); this distance must be measured internally in the left half carcass after split down).

- Hind limb length (F): Distance from the tarsalmetatarsal joint surface to cranial edge of the pubic bone (Figure 1: $\mathrm{b} \rightarrow \mathrm{c}$ ); this distance must be measured internally in the left half carcass after split down).

- Width of the buttocks (G): Maximal length between both greater trochanters of the femur (Figure 2: $d \rightarrow d^{\prime}$ ).

- Width of the thorax (ThW): The greatest width of the chest of the carcass at the level of the caudal edge of the scapula (Figure 2: $\mathrm{e} \rightarrow \mathrm{e}^{\prime}$ ).

- Lumbar circumference (LC): Carcass circumference around the buttocks at the level of the maximum width of the greater trochanters (Figure 3 ).

- Thorax circumference $(\mathrm{ThC})$ : The circumference measured between the spinous process of the eighth thoracic vertebra (Figure 3: f) and the xiphoid cartilage of sternum, just behind the elbow (Figure 3: g).

- Thorax depth (ThD): Maximal length between the spinous process of the eighth thoracic vertebra and the xiphoid cartilage of sternum, just behind the elbow (Figure 3: $\mathrm{f} \rightarrow \mathrm{g}$ ).

- Carcass compactness: The relation between hot carcass weight $(\mathrm{HCW})$ and carcass length $(\mathrm{HCW} / \mathrm{L}$, $\mathrm{g} \mathrm{cm}^{-1}$ )

- Leg compactness (percentage): The relation between the width of the buttocks and leg length $(\mathrm{G} / \mathrm{F} \times 100)$.

It is possible take other linear measurements with other specific purposes, describing the anatomical points of reference.

\subsection{Meat quality attributes in carcass}

\subsubsection{Meat colour}

The CIELAB colour space (CIE 1976) is the most complete method in meat colour estimation. Colour appreciated in the muscle rectus abdominis. This muscle is used because its colour may be representative of normal skeletal muscle myoglobin content, and the effects of the muscle activity do not significantly affect the cited pigment content (Colomer-Rocher et al. 1988). Mota-Rojas et al. (2012) have previously used this muscle to measure meat colour in guinea pigs.

Going to the histological and textural differences, so does the muscle longissimus thoracis et lumborum. Thus, the colour of these two muscles depends essentially on the nutrition (iron content) and age of the animal. However, because of in guinea pig the size of this muscle (longissimus thoracis et lumborum) could be too small, measuring colour on it could be very difficult. Muscle rectus abdominis is devoid of external fat; therefore, no need to clean or cut the muscle to see its colour. Colour must be measured after slaughtering (15 min and $45 \mathrm{~min}$ ) and after chilling time.

\subsubsection{Muscle $p H$}

$\mathrm{pH}$ is measured in situ by insertion of a thin electrode after incision on muscle longissimus lumborum. $\mathrm{pH}$ must be measured at three time points: $15 \mathrm{~min}$ and $45 \mathrm{~min}$ after slaughter and after chilling.

\subsection{Body condition score (BCS)}

BCS is assessed according to Ara et al. (2012). They described a 1 to 5 rating system, well correlated with body mass index $(0.87)$, total fat $(0.83)$ and dorsocervical caudal fat (0.86). The BCS includes the following five categories: 
- BCS 1: Totally emaciated, with the cervical vertebrae, the processes of the thoracic and lumbar vertebrae and sacral tuberosity completely palpable.

- BCS 2: Higher body mass but are still palpable all bony structures mentioned in BCS 1 .

- BCS 3: It is not possible to feel the cervical vertebrae and ribs, unless more pressure is exerted. Other bone structures are still palpable.

- BCS 4: Besides the mentioned, BCS 3 is no longer possible to feel the processes of the thoracic or lumbar vertebrae. It is still palpable sacral tuberosity but accompanied by soft tissue.

- BCS 5: All that can be felt is slightly sacral tuberosity. The neck comes completely cylindrical to the touch.

\subsection{Perirenal and pelvic fat deposits score (PFS)}

Perirenal and pelvic fat deposits are measured by visual assessment of the importance of fat accumulation overlying the kidneys and the pelvic cavity.

- PFS 1: The kidneys are only covered in its caudal extremity. A thin layer of fat covers the pelvic cavity.

- PFS 2: The kidneys are partially covered with fat. The fat deposited in the pelvic cavity is apparent and medium thick. However, no fat accumulations occur in clusters.

- PFS 3: The two kidneys are fully covered and the overlying layer is very thick. The pelvic cavity presents fat accumulation in the form of very coarse and numerous clusters.

Also, the colour of fat deposit can be measured using the CIELAB colour space before and after chilling.

\section{Jointing procedure and order of cutting}

The carcasses are split down the vertebral column, being the two sides as symmetrical as possible. Each half carcass must contain the perirenal and pelvic fat deposits. These fat deposits should be included in the separation results and should be considered part of total side carcass fat.

Both weights of the half carcasses should be recorded. The left half carcass is designed to jointing prior to the cutting dissection in four anatomical regions, in a modified procedure described by Colomer-Rocher et al. (1987) as shown in the scheme in Figure 4. Before jointing procedure, perirenal and pelvic fat deposits located in the internal part of the carcass should be removed and weighted.

The left side is divided into four primal cuts: shoulder, long leg, neck and ribs and flank.

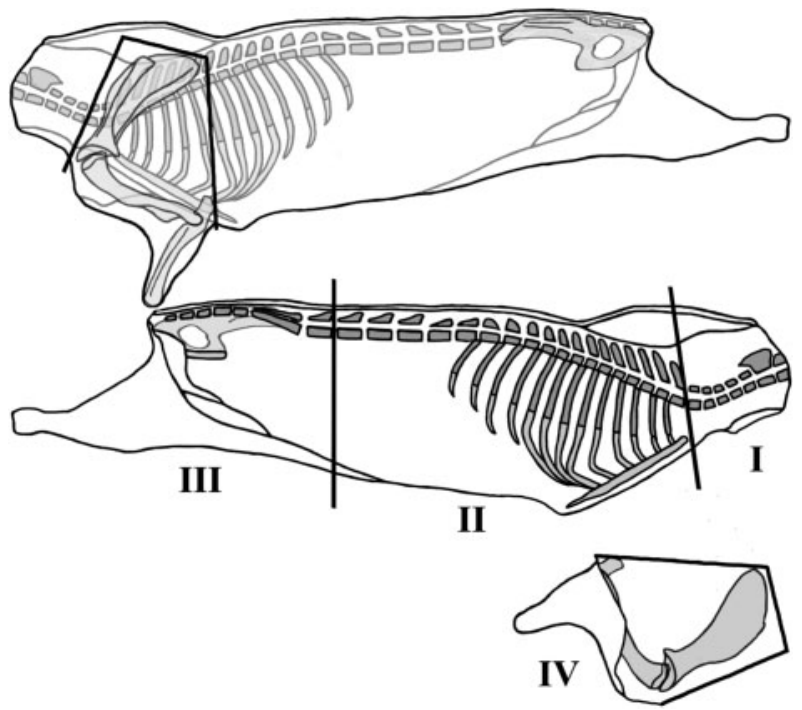

Figure 4. Scheme for jointing the left half guinea pig carcass into a 4 anatomical regions: I, Neck; II, Ribs; III, Long leg; and IV, Shoulder.

- The shoulder is separated from the side according to the standardized jointing procedure for goat carcasses (Colomer-Rocher et al. 1987). This cut is defined by four straight cutting lines (Figure 4, I: Shoulder).

- Anatomical points of reference: It is an articulation point between the penultimate and the last lumbar vertebrae; the cut is made perpendicular to the sagittal plane of the carcass (Figure 4, II: Long leg).

- Anatomical points of reference: It is an articulation point between the last cervical and first thoracic vertebrae; the cut is made following the cranial edge of the first rib (Figure 4, III: Neck).

- The removal of the other three joints leaves the ribs as the remaining anatomical region (Figure 4, IV: Ribs).

\section{Tissue distribution}

Tissue distribution is performed in the left carcass side. After weighing, each cut is separated into dissectible muscles, sub-cutaneous fat, inter-muscular fat, bones, skin and remainder (major blood vessels, ligaments, tendons, nerves and thick connective tissue sheets associated with some muscles). It is recommended to perform this procedure in a controlled temperature with the objective of avoiding moisture losses (no more than $5 \%$ of moisture loss must be permitted).

All subsequent calculations for carcass composition and fat partitioning should be based on expressing separable components as a proportion of the sum of 
these components in the part or the whole, comprising $100 \%$.

It could be very interesting for researcher to weigh the neck, axillary and inguinal fat deposits in guinea pigs, as it has been previously described by Blasco and Ouhayoun (1993) in rabbits.

In conclusion, this study is to suggest practical and normalized method to analyse the guinea pig carcass morphological characteristics allowing their evaluation based on anatomical guidelines. This proposal of standard method, modified from the standard method proposed for goats by Colomer-Rocher et al. (1987), could be used for researchers and technicians to compare data of these animals under different conditions.

\section{Acknowledgements}

This study has been financed by the research project 'Normalización del estudio y caracterización de la calidad de la canal y de la carne de cuy' from the Universidad Nacional de Chimborazo, Ecuador. Authors are very grateful to Roberto Reyes, DVM, for his technical assistance with the carcass pictures.

\section{ORCID}

Davinia Sánchez-Macías (iD http://orcid.org/0000-00015626-4249

\section{References}

Ara G, Jiménez R, Huamán A, Carcelén, F, Díaz D. 2012. Desarrollo de un índice de condición corporal en cuyes: relaciones entre condición corporal y estimados cuantitativos de grasa corporal [Body condition score development in guinea pigs: relationship between body condition score and quantitative estimates of body fat]. Revista de Investigaciones Veterinarias del Perú. 23:420-428.

Blasco A, Ouhayoun J. 1993. Harmonization of criteria and terminology in rabbit meat research. Revised proposal. World Rabbit Sci. 4:93-99.

CIE Commission Intertnational de L'Eclairage. 1976. Official recommendations on uniform colour spaces, colour differences equations and metric colour term. Supplement no. 2 to CIE publication no. 15. Colorimetry, Paris.

Colomer-Rocher F, Morand-Fehr P, Kirton AH. 1987. Standard Methods and procedure for goat carcass evaluation, jointing and tissue separation. Livest Prod Sci. 17:149-159.
Colomer-Rocher F, Morand-Fehr P, Kirton AH, Delfa R, Sierra Alfranca I. 1988. Método Normalizado para el despiece de las canales caprinas y procedimientos para la evaluación de sus caracteres [Standard methods for goat carcass jointing and procedures for the evaluation of its characteristics]. Madrid: Ministerio de Agriculatura, Pesca y Alimentación. Instituto Nacional de Investigaciones Agrarias; p. 41.

Indecopi. 2006. NTP 201.058. Carne y productos cárnicos. Definiciones, clasificación y requisitos de las carcasas y carne de cuy (Cavia porcellus) [Meat and meat products. Definition, classification and requirements for guinea pig carcass and meat]. Lima, Perú: Instituto Nacional de Defensa de la Competencia y de la Protección de la Propiedad Intelectual.

Kouakou NDV, Grongnet JF, Assidjo NE, Thys E, Marnet PG, Catheline D, Legrand P, Kouba M. 2013. Effect of a supplementation of Euphorbia heterophylla on nutritional meat quality of Guinea pig (Cavia porcellus L.). Meat Sci. 93:821-826.

Lammers PJ, Carlson SL, Zdorkowski GA, Honeyman MS. 2009. Reducing food insecurity in developing countries through meat production: the potential of the guinea pig (Cavia porcellus). Renew Agr Food Syst. 24:155-162.

Matthiesen T, Nyamete F, Msuya JM, Maass BL. 2011. Importance of guinea pig husbandry for the livelihood of rural people in Tanzania: a case study in Iringa Region. In proceedings book of abstracts of Tropentag Conference; Oct 5-7; Bonn: International Research on Food Security, Natural Resource Management and Rural.

Mota-Rojas D, Trujillo-Ortega ME, Becerril-Herrera M, Roldán-Santiago $\mathrm{P}$, González-Lozano M, Guerrero-Legarreta I. 2012. Efecto del método de sacrificio sobre las variables críticas sanguíneas y consecuencias sobre la bioquímica de la carne de cobayo (Cavia porcellus) [Effects of slaughtering method on critical blood indicators and on biochemical of the guinea pig meat]. Revista Científica de la Facultad de Ciencias Veterinarias de la Universidad de Zulia. XXII:51-58.

Núñez-Valle D, Cevallos-Velastegui LP, MoralesdelaNuez A, Castro N, Argüello A, Sánchez-Macías D. 2014. Postmortem $\mathrm{pH}$ evolution in four muscles and onset, state and resolution of rigor mortis of guinea pigs (Cavia porcellus) carcass. J Anim Sci. 92, E-Suppl. 2/J. Dairy Sci. 97, E-Suppl. 1

Walstra P, Merkus GSM. 1995. Procedure for assessment of the lean meat percentage as a consequence of the new EU reference dissection method in pig carcass classification. Zeist: ID-DLO Research Branch. 